Article

\title{
The Regional Governance of Energy-Neutral Housing: Toward a Framework for Analysis
}

\author{
Laura de Leeuw and Martijn Groenleer* \\ Tilburg Center for Regional Law and Governance, Tilburg Institute of Governance, Tilburg University, \\ 5037 AB Tilburg, The Netherlands; laura_deleeuw@hotmail.com \\ * Correspondence: m.l.p.groenleer@tilburguniversity.edu; Tel.: +31-13-4663547
}

Received: 7 August 2018; Accepted: 8 October 2018; Published: 16 October 2018

\begin{abstract}
Regions are expected to play a key role in realizing international, European, and national climate and energy goals. Also regions in the Netherlands are working toward these goals, taking initiatives toward an energy-neutral built environment by 2050. However, it remains unclear how such efforts and other socially innovative activities can best be described and how variation between them in terms of governance can be explained. In this article, we develop a framework for analyzing the governance of regional energy-neutral housing initiatives. We ask what factors shape regional climate and energy governance, particularly regional efforts to increase the efficiency of urban dwellings. We answer this question using a subnational comparative method and a most similar case design, focusing on three Dutch regions: Utrecht, Noord-Brabant and Drenthe. Based on document analysis and 24 semi-structured interviews, we find that the regional governance of energy-neutral housing initiatives is primarily driven by existing social networks in the regions, and less determined by local characteristics of the built environment. Thus, regional governance seems to have generated solutions that are supported by regional actors. Nonetheless, as these solutions are not entirely tailored to the regional situation, functionally speaking, a key question for future research is how effective these solutions will be.
\end{abstract}

Keywords: climate and energy governance; customization; effectiveness; energy-neutral housing; legitimacy; most similar case design; regional governance; social innovation; social networks; subnational comparative method

\section{Introduction}

Buildings are among the most pervasive and durable forms of human infrastructure, and they account for some 30 percent of $\mathrm{CO}_{2}$ emissions [1,2]. To increase the energy efficiency of buildings, various goals have been set and policies designed at the international and European levels. Alone, however, these goals and policies are insufficient. National action is needed as well, especially in countries already lagging in the transition toward more sustainable energy systems, such as the Netherlands [3]. In 2013, as part of the National Energy Agreement (NEA), Dutch governmental, private and societal actors agreed to work together toward an energy-neutral housing stock by 2050 . Achieving this goal will require increasingly intense efforts. Climate experts in the Netherlands estimate that 50,000 houses per year will need to be made more energy efficient up to 2021, with this number increasing to 200,000 houses per year by 2030 [4].

To deal with this enormous challenge, both worldwide and in the Netherlands, the local level and particularly, regions have been put forward as spaces for action. Rather than an actor, the region is understood as an arena in which governmental, private and societal actors come together to address complex, transboundary problems [5]. The assumption is that collaboration between these actors within regions could generate innovative solutions tailored to region-specific characteristics. 
The tailored nature of these regional solutions would render them not only effective, but also legitimate. For this reason, recent policy reports argue that regions in the Netherlands should be given more leeway for differentiation in governance [6-8], including allowances for tailor-made solutions to (transboundary) climate and energy problems.

Specifically, policy programs, reports and studies on energy-neutral housing claim that national and international goals for energy-neutral housing can best be achieved at the regional level, as here 'place-based' strategies can be developed, which at the same time benefit from 'economies of scale'. An Association of Dutch Municipalities (VNG) program on energy efficiency in the built environment, for instance, views regional collaboration as making 'optimal use of local "best persons" and the "regional DNA"' [9] (p. 12). The Dutch Minister of Housing has cited exploring opportunities in the regional context as 'an important part of the transition' [10] (p. 3). Moreover, a recent study on energy-neutral housing emphasized the need for an approach that 'provides insight in the diversity of variables for every region and tailor-made regional solutions' [11] (p. 11).

Scientific research on regional governance of the climate and energy transition is scarce, however. First, regions have been studied mainly from a territorial perspective, focusing on structure and form [12]. Much less attention has been paid, at least from a governance perspective, to the region as a 'fluid' space (but see [13-15]), in which strategies are developed to tackle transboundary problems by a range of public, private, and societal actors. Yet, it is this fluid region that is assumed to be an appropriate space for linking up these actors operating at multiple levels of governance [5]. Second, many recent studies on energy-neutral housing focus on the behavior of individual citizens when it comes to the adoption of energy efficiency measures $[16,17]$. There is much less research on the complex context, characterized by a great variety of stakeholder perspectives and interests and institutional structures and governance arrangements in which energy efficiency measures in the housing sector are developed. Third, and finally, much of the available research focuses on local governments or cities [18-20]. As a result, we lack knowledge on the role of regions in climate and energy governance.

To better understand the role of 'the region' in climate and energy governance, and in particular, in initiatives and efforts to attain an energy-neutral housing stock, research is needed. This is especially so because of the remarkable variety in the regional governance solutions applied. Despite ultimately aiming to meet the same national goals, and even in such a relatively small country as the Netherlands, regional solutions are often strikingly different. Intermediary regional goals vary and also the way key stakeholders are involved differs. We do not yet know to what extent customization of policies to regional specificities serves as an explanation of these differences. Studying this variation by exploring the factors on which regional governance is conditional is important because we want to know whether regional solutions are indeed tailor-made and thus fit regional characteristics. Knowing whether regional governance solutions are customized to regional problems can provide us with preliminary indications of the likelihood that these solutions will be both effective and legitimate. Hence, this article investigates the following question: What factors shape regional climate and energy governance, particularly regional initiatives to increase the energy efficiency of urban dwellings, in the Netherlands?

To answer this question, we zoom in on the realization of an energy-neutral housing stock in the non-profit rental sector. By 'energy neutral', we mean that the total amount of energy used by a dwelling on an annual basis is approximately the same as the amount of renewable energy generated at the site of the dwelling. In the academic and professional literature various other terms are also used, such as the abovementioned Net-Zero Energy housing [21] and Nearly Zero-Energy housing [22,23], both abbreviated as 'NZE' housing. These houses have a very high energy performance, meaning they use very little energy, and the energy they consume comes from renewable sources. As per 2017, the total Dutch housing stock consisted of some 7.7 million dwellings: 4.3 million were owner-occupied (55 percent), one million were privately owned rental properties (12 percent), and 2.3 million were rental properties owned by non-profit housing associations (30 percent) [24]. It is mostly with regard to this last category, non-profit (or social) housing that various kinds of regional governance solutions have emerged, beyond uniform national policy goals and adaptations thereof at the regional and local 
levels. These have not prominently featured in earlier work focusing on energy-efficient building in the Netherlands [25-27], and thus demand our attention.

We define regional governance, our outcome variable, as the deliberate efforts of a variety of public, private, and societal actors at a multitude of levels to achieve goals, coordinate actions, and make decisions to address a specific substantive problem in a certain geographic area $[5,12]$. Regional governance can be seen as an important social innovation in itself, with regions serving as 'living labs' for innovation, technologically, as well as socially. The idea then is to experiment with and learn from local and regional solutions. What works and what does not, also in terms of new roles, new responsibilities and new relationships between actors. We expect regional governance to be determined by the nature of the regional problem and the possibilities for regional solutions. At the same time, it will likely be driven by the collaboration structures and cultures that already exist within the regional community [28]. We expect to find strong interaction between specific regional governance arrangements and the characteristics of the climate and energy problem, which may vary regionally, and the prevailing social networks within a region.

We used a subnational comparative method and a most similar systems design to study the Dutch regions of Utrecht, Noord-Brabant, and Drenthe. We obtained data from both publicly available and confidential documents and by conducting 24 in-depth, semi-structured interviews with key stakeholders in the selected regions.

This article starts with a brief generic overview of national policy goals and regional initiatives concerning realization of an energy-neutral housing stock (Section 2). To guide our empirical investigation, we subsequently construct an analytical framework (Section 3) and detail the methodological approach applied (Section 4). Next, we present and discuss our empirical findings, examining climate and energy governance in the regions of Utrecht, Noord-Brabant, and Drenthe (Sections 5 and 6). We conclude by answering the research question, elaborating on both the contribution and limitations of the research, and outlining avenues for future work (Section 7).

\section{An Energy-Neutral Housing Stock: European, National and Regional Policies and Governance}

\subsection{European and National Policy Goals}

Around 40 percent of the energy that is consumed in the European Union (EU) is consumed by buildings. Much of this energy consumption is by the residential sector. Indeed, approximately 30 percent of the energy used by the total building stock is consumed by dwellings [1].

The large amount of $\mathrm{CO}_{2}$ emissions produced, together with the fact that existing buildings will dominate the housing stock for the coming 50 years, has generated significant interest in energy efficiency in the housing sector [1,2]. In Europe and in the Netherlands, policies have thus been developed to increase energy efficiency in this sector. The Netherlands implemented the EU Energy Performance of Buildings Directive (EPBD) in 2008, and in 2012 it formulated the Energy Saving Covenant for the Rental Sector [29,30]. Moreover, the Dutch Energy Agreement of 2013 set the objective of achieving an entirely energy-neutral housing stock by 2050, including both non-profit and owner-occupied housing. This goal was endorsed nationally by public, private, and societal actors.

\subsection{Regional Governance Solutions}

To realize these European and national ambitions, tailor-made solutions are expected to be delivered through the multi-level, multi-actor workings of regional governance. Indeed, economic and social initiatives of citizens and businesses in the Netherlands increasingly play out at the regional level $[8,31]$. By enabling a connection between abstract sustainability policies and the everyday lives of citizens, the region is considered to have the potential for creating legitimate solutions [32,33]. Furthermore, especially in the field of climate change policy it is argued that broad participation of actors in bottom-up governance processes contributes to the necessary acceptation of these policies on the ground [34]. 
As for effectiveness, consensus-oriented collaboration between public and private actors is often considered to be more effective than bureaucratic government in tackling complex, transboundary problems such as climate change [35]. This so-called collaborative governance is assumed to enhance the problem-solving capacity of the involved actors and the creation of public value [36-38]. Specifically, in the field of environmental policy, multi-actor governance ensures that locally held knowledge and preferences of actors active in the region are effectively incorporated in the governance process $[39,40]$.

\subsection{Toward Energy-Neutral Housing}

In the Netherlands, regional policies have recently been developed to establish an energy-neutral built environment by 2050, in both owner-occupied housing and in the non-profit, or the social, housing sector. For the owner-occupied sector, there is a nationwide program with a regional approach led by the VNG. This program supports the regions in advancing the energy efficiency of privately-owned dwellings. Essentially, this is a top-down initiative organized following the standard administrative boundaries of Dutch regions.

Besides this top-down program for the owner-occupied sector, strategies have emerged in several Dutch regions that also incorporate the non-profit housing sector. Municipalities, housing associations, business parties, the provincial administration and environmental organizations have formulated ambitions together and pooled their capacity to increase the number of energy-neutral dwellings. These regional governance strategies are the focus here. To analyze these strategies, we present a tentative theoretical framework in Section 3.

\section{Theoretical Framework: Investigating Regional Governance}

\subsection{The Region}

Governance of and particularly in 'the region' is the outcome variable of interest. This requires us, first, to explicate our concept of the region. At the core of the contemporary scientific discussion on what the region is and how it should be conceptualized lies the difference in approach between the territorial perspective and the relational perspective [41].

From a territorial perspective, 'the region' is defined by 'bounded spatial units' [42] (p. 263). This perspective centers on borders and preset, defined territories in space. An example of a region defined in a territorial way is the formal administrative unit, such as departéments in France, Länder in Germany and provinces in the Netherlands. In contrast, the relational perspective centers on concepts related to 'interspatial relations, flows and networks' [42] (p. 263). Thus, from a relational perspective, a region is defined as an entity shaped by networks and social relations, creating complex interconnectedness and flows on a territorial scale. This means that the boundaries we perceive between regions are the result of formal and informal networks and connections. An 'energy region', from such a perspective, would be an-often temporary-network of parties formed around the issue of, for instance, establishing a regional energy strategy and the joint implementation of such a strategy.

Both the territorial perspective and the relational perspective have been criticized by authors as being too one-sided. These authors adopt a hybrid perspective instead. They perceive regions to be made up of territorial specificities that are, at the same time, defined by struggles between political actors and civil society. This can be called a moderate approach in which both territorial elements and relational elements are combined $[43,44]$. The present article adopts such a moderate perspective on the region. Space and place thus continue to be important, as we still focus on a geographic area, but the region as we allude to it here is not necessarily bounded to a specific, preset territory. It is potentially more variable-'fluid' - consisting of networks and connections around a particular, substantive problem $[5,12]$. 


\subsection{Regional Governance}

Progress has been made in the study of regional governance, both from a territorial perspective (focusing on form and structure and, e.g., on intermunicipal relations) and from a relational perspective (concentrating on collaborative governance and social networks). However, research adopting a moderate perspective is less advanced. Adoption of such a perspective requires a greater focus on the capacity and purpose of regional governance [12] (p. 273). Capacity pertains to how actors organize decision-making, determine means of action, secure resources, and eventually, act on regional issues, beyond jurisdictional, sectoral, and functional borders. Purpose refers to the objective that actors seek to achieve regarding a regional problem. Regional governance approached from a moderate perspective may well be based on consensus or cooperation, but this is not necessarily the dominant mode. Non-consensus driven regional governance can also be effective. Indeed, there are various modes of coordination, based on power, interests, values, and ideas [12].

This perspective on regional governance is grounded in part on urban regime theory $[45,46]$. Barnes and Foster have argued that because urban regime theory is based on one jurisdiction, it is unsuitable for the study of regional governance [12]. Other scholars have further developed the concept of the urban regime into that of the regional regime [46,47]. A regional regime is defined as 'the informal arrangements by which autonomous and semiautonomous actors work together to make and carry out governing decisions relevant to a specific region' [46] (p. 51). We build on this definition, understanding regional governance as the deliberate efforts of a variety of public, private and societal actors to achieve goals, coordinate actions and make decisions in a regional setting $[5,12]$. Figure 1 visualizes the moderate perspective adopted in this study, contrasting it with the territorial and relational perspectives, while also showing overlap and the complementarity of the perspectives.

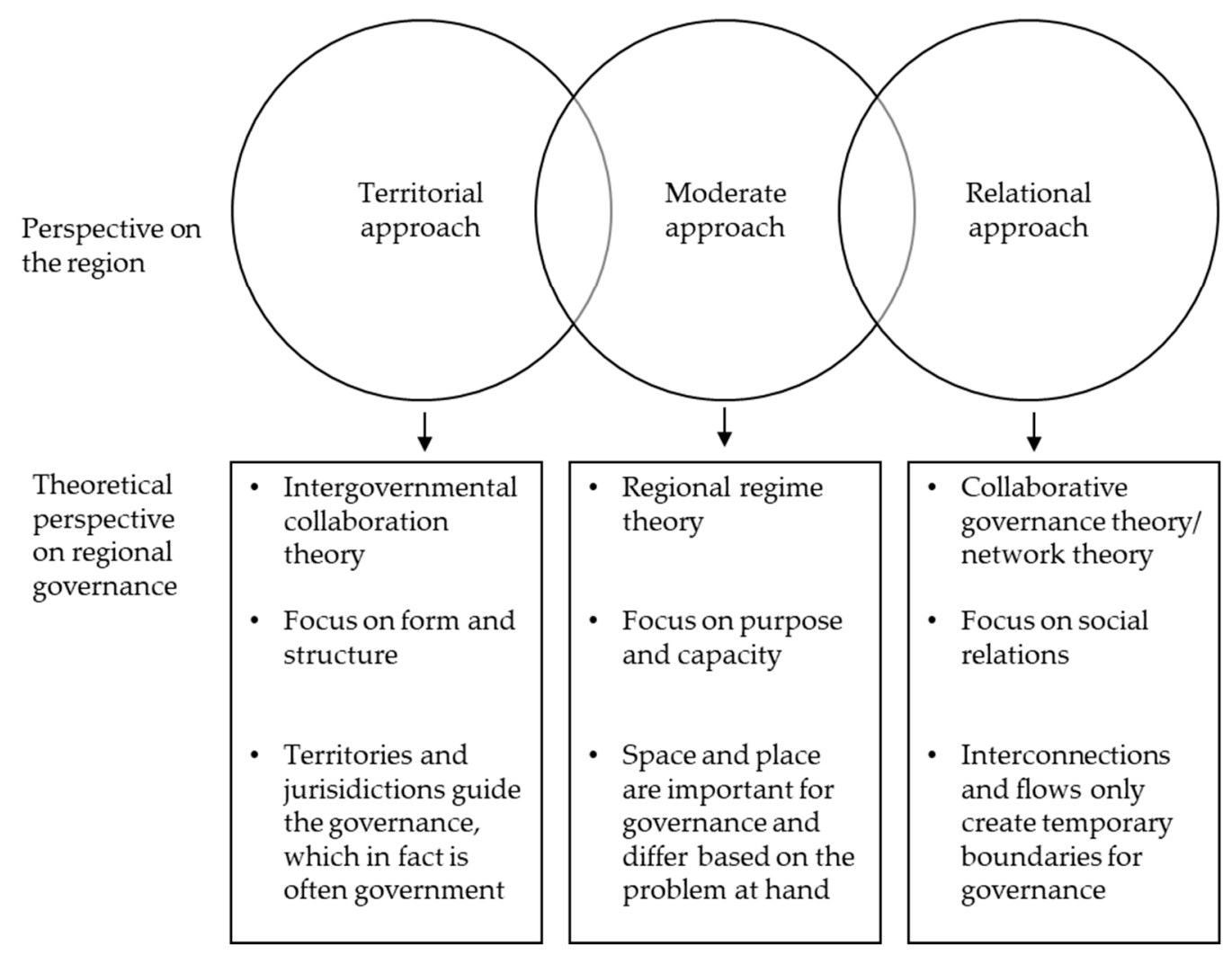

Figure 1. Perspectives on the region and regional governance.

Conceptualized as such, regional governance can be analyzed along the following four dimensions [12,45,47,48]: Agenda, actor group, regional capacity, and mode of alignment. The first dimension, the agenda, addresses the distinct set of regional problems. According to Barnes and Foster, 
the agenda dimension can be operationalized by studying the framing, assessment and comprehension of the regional problems. The second dimension, the actor group, refers to the governing coalition that is formed around the agenda. Indicators characterizing the actor group are its commitment, composition and leadership. The third dimension is regional capacity, which consists of all the resources needed for pursuit of the agenda. These are brought in to be used by the members of the actor group. Indicators that describe regional capacity are information, expertise, financial resources and authority [12]. The fourth and final dimension concerns the mode of alignment or scheme of cooperation, indicating the way the actors interact and work together to implement the agenda [45,47]. Table 1 summarizes the dimensions of regional governance used in this study, together with the questions employed to operationalize the dimensions.

Table 1. Dimensions of regional governance.

\begin{tabular}{|c|c|c|}
\hline \multicolumn{2}{|c|}{ Regional Governance } & \\
\hline \multicolumn{2}{|r|}{ Dimensions } & Questions \\
\hline \multirow{3}{*}{ Agenda } & Framing of the agenda & $\begin{array}{l}\text { Are the vision, goals, alternatives and priorities effectively } \\
\text { formulated, in light of the regional problem and context? }\end{array}$ \\
\hline & $\begin{array}{l}\text { Assessment of the agenda } \\
\text { by involved actors }\end{array}$ & $\begin{array}{l}\text { Are the goals on the agenda deliberatively set by the actors } \\
\text { involved? Is support and opposition regarding the agenda } \\
\text { clear? Is there a shared sense of urgency? }\end{array}$ \\
\hline & $\begin{array}{l}\text { Broader comprehension of } \\
\text { the agenda }\end{array}$ & $\begin{array}{l}\text { Is the agenda broadly communicated in the region? Is it } \\
\text { widely known among regional actors? }\end{array}$ \\
\hline \multirow{3}{*}{ Actor group } & $\begin{array}{l}\text { Composition of the actor } \\
\text { group }\end{array}$ & $\begin{array}{l}\text { Who is at the table, and who is not? Are key regional } \\
\text { stakeholders needed for success included? }\end{array}$ \\
\hline & $\begin{array}{l}\text { Commitment to goals and } \\
\text { group }\end{array}$ & $\begin{array}{l}\text { Are the involved parties committed to the goals and the } \\
\text { group? }\end{array}$ \\
\hline & Leadership & $\begin{array}{l}\text { Is there regional leadership to realize the agenda? Is it clear } \\
\text { who does what and when? }\end{array}$ \\
\hline \multirow{3}{*}{$\begin{array}{l}\text { Regional } \\
\text { capacity }\end{array}$} & Authority & $\begin{array}{l}\text { Does the actor group have the required authority in and } \\
\text { beyond the region? }\end{array}$ \\
\hline & Information and expertise & $\begin{array}{l}\text { Is the necessary information and expertise available in the } \\
\text { region? }\end{array}$ \\
\hline & Financial resources & $\begin{array}{l}\text { Are sufficient financial resources available to realize the } \\
\text { agenda? }\end{array}$ \\
\hline $\begin{array}{l}\text { Mode of } \\
\text { alignment }\end{array}$ & $\begin{array}{l}\text { Interaction and way of } \\
\text { working together }\end{array}$ & $\begin{array}{l}\text { How do actors interact with each other? How do parties } \\
\text { work together in order to realize the agenda? }\end{array}$ \\
\hline
\end{tabular}

\subsection{Analyzing Regional Governance}

As we do not perceive regional governance from a purely relational perspective, but add elements of the territorial perspective, we consider place to still be of importance. Regional governance, as argued by Barnes and Foster, is likely to vary based on 'place, time and goal, reflecting issue differentiation and evolution of alternative political economies and cultures' [12] (p. 276).

In their work on regions and multi-level governance, Hooghe and Marks combine this idea of regional issue differentiation with variation in collaboration cultures and structures as the two factors on which regional governance is conditional [28]. In their view, regional governance depends on both the functional logic of scale and the social logic of community. The functional logic of scale, as we interpret it here, relates to the specific characteristics of the regional problem and concomitantly, the possibilities for regional solutions. These characteristics may lead one region to develop different policies and institutions than another.

The social logic of community relates to the prevailing social networks and the regional culture and identity. The literature generally states that conditions present at the outset of a collaboration 
influence the way stakeholders work together. In their overview article on collaborative governance, Ansell and Gash identified both the initial trust level between stakeholders and power/resource imbalances between stakeholders as important structural factors on which collaborative governance is conditional [35]. These factors may also lead relations in one region to evolve in different ways than in another region.

Both regional issue differentiation and variation in collaboration cultures and structures may be affected by geographic conditions, such as the size of a region and its location in a country. Table 2 summarizes the dimensions of regional governance that we use in this study, together with the logics they follow and the questions used to operationalize these dimensions.

Table 2. Factors on which regional governance is conditional.

\begin{tabular}{|c|c|c|}
\hline Logic & Dimensions & Questions \\
\hline \multirow[b]{2}{*}{ Functional } & $\begin{array}{l}\text { Characteristics of the } \\
\text { regional problem }\end{array}$ & $\begin{array}{l}\text { What is the nature of the problem? Is it a regional problem in the } \\
\text { sense that it crosses various kinds of borders? }\end{array}$ \\
\hline & $\begin{array}{l}\text { Possibilities for } \\
\text { regional solutions }\end{array}$ & $\begin{array}{l}\text { What are the possibilities for regional solutions? Is there a } \\
\text { potential for formulating regional goals and amassing } \\
\text { regional capacity? }\end{array}$ \\
\hline \multirow{3}{*}{ Social } & $\begin{array}{l}\text { Regional collaboration } \\
\text { culture }\end{array}$ & Is there a strong collaboration culture in the region? \\
\hline & $\begin{array}{l}\text { Regional collaboration } \\
\text { structure }\end{array}$ & $\begin{array}{l}\text { What networks on the specific issue of interest already exist in } \\
\text { the region? }\end{array}$ \\
\hline & & $\begin{array}{l}\text { Are these networks typified as either strong or weak? What } \\
\text { repeated interactions, complex interdependencies and trust } \\
\text { relationships can be identified? }\end{array}$ \\
\hline
\end{tabular}

\subsection{Toward a Framework for Analysis}

We thus expect regional governance to produce innovative solutions that are determined by a functional logic, while also being driven by a social logic. More precisely, we expect to find strong interaction between the specifics of the regional governance arrangements and the characteristics of the problem as it manifests regionally - in our study challenge of achieving an energy-neutral housing stock - and the social networks that already exist in a region around the problem. Figure 2 displays our tentative framework for analysis.

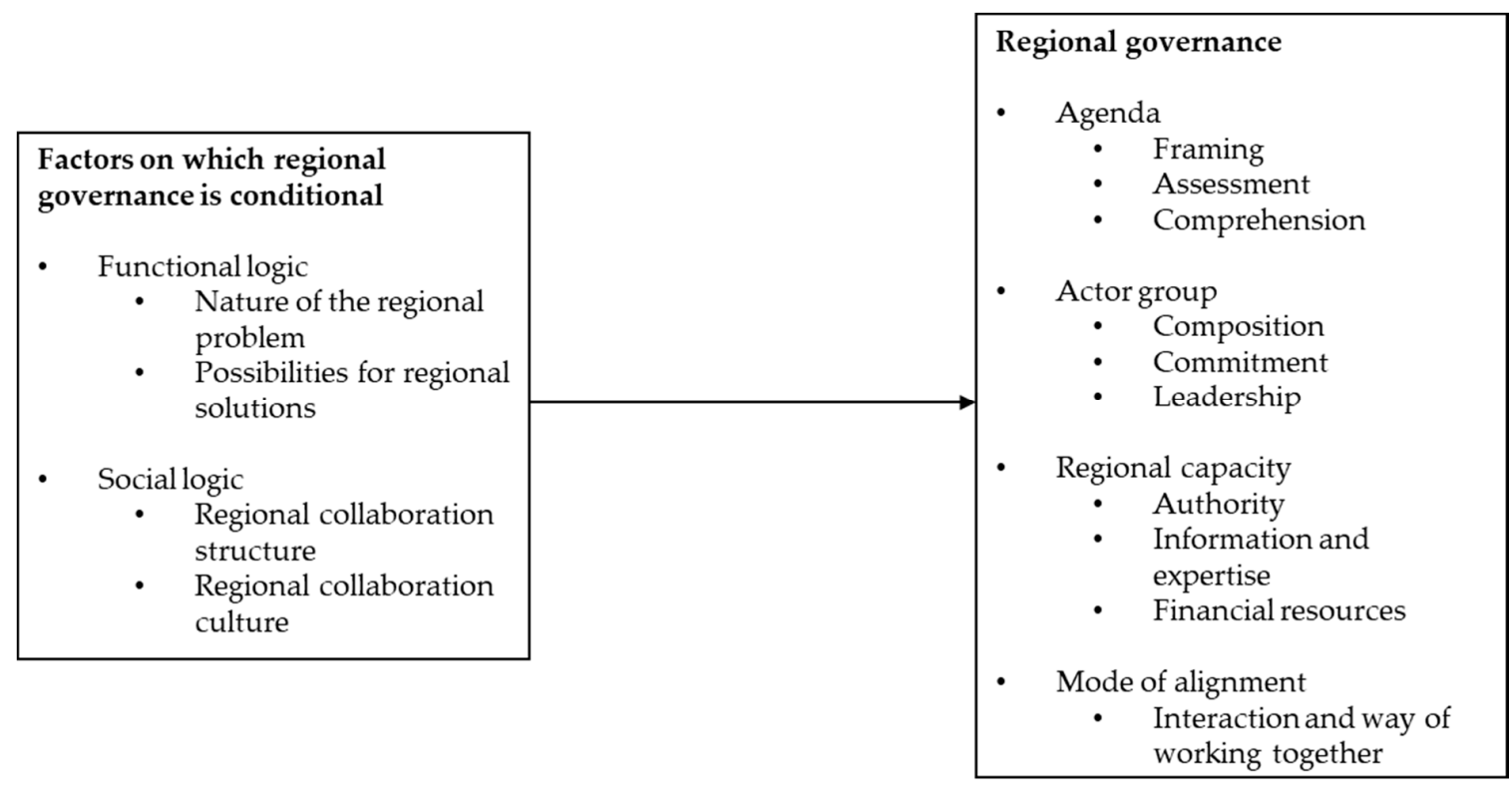

Figure 2. Framework for analysis. 


\section{Method and Data: Qualitative, Comparative Case Study}

\subsection{Comparative Method}

We made use of the 'subnational comparative method' [49]. In this method, subnational units, in our study regions, are compared to increase the number of observations and make controlled comparisons. This increases the likelihood of attaining valid causal inferences in small- $N$ research. The subnational comparative method overcomes the 'whole-nation bias', increasing sensitivity to within-nation variation, and in particular, to the spatially uneven nature of major societal developments and trends in a country.

To compare regions within in a single country (in our study: the Netherlands), we also made use of a 'most similar case' design [50]. Indeed, the national context of the Netherlands creates similarities of a political, economic, financial, legal, cultural, historical and ecological nature, making at least some Dutch regions 'as similar as possible'. These similarities enable us to identify and ultimately reduce the potential explanatory factors for differences between regions [50-53]. Use of this method helped us to focus on the functional and social logics on which, we put forward, regional governance is conditional.

In reality, two cases are almost never the same in all but one possible explanatory factor; and there are often multiple causal pathways to the same outcome. For that reason, we used the subnational comparative method and the most similar case design in a more general way, primarily to systematize our research. We compensated for our method's practical weaknesses by process tracing; that is, we attempted to establish the causal significance of multiple possible explanatory factors by tracing a process from expected 'cause' to observed 'effect' $[53,54]$.

\subsection{Case Selection}

Given the moderate perspective on 'the region' adopted in this research, including both relations and territory, we focused on Dutch provinces as cases of regions. Regional climate and energy governance has often emerged within the geographic context of the province over the last five years, without the province as an institutional actor necessarily dominating arrangements or structures. This focus produced a degree of similarity across our cases with regard to the institutional setting, allowing us to zoom in on differences regarding the scale and community factors outlined above.

Relying on an overview of possible cases provided by 'Energiesprong' [55], an innovation program to stimulate energy-neutral building in The Netherlands that ran until the end of 2016, we selected, as cases, the three Dutch regions of Noord-Brabant, Drenthe and Utrecht. In these regions, regional actors had concluded a deal or set goals in relation to realization of an energy-neutral housing stock in the non-profit housing sector. Moreover, they had at least begun to put these deals or goals into practice. Yet, from the first glance differences could be observed in the governance of these regions' initiatives toward energy-neutral housing, starting with the deals concluded or goals set. Figure 3 depicts these, providing an overview of the selected regions.

Regions with deals or goals focusing only on the owner-occupied sector or initiated by national actors were not included in the set of possible cases. Regions where no steps had been taken to put deals or goals into practice were similarly excluded. At the time our research was carried out (October 2016-February 2017), the region of Friesland was still in the process of negotiating a deal, while the Zeeland region finalized a deal in March 2016, but had not yet started implementation. We therefore did not include either region. 


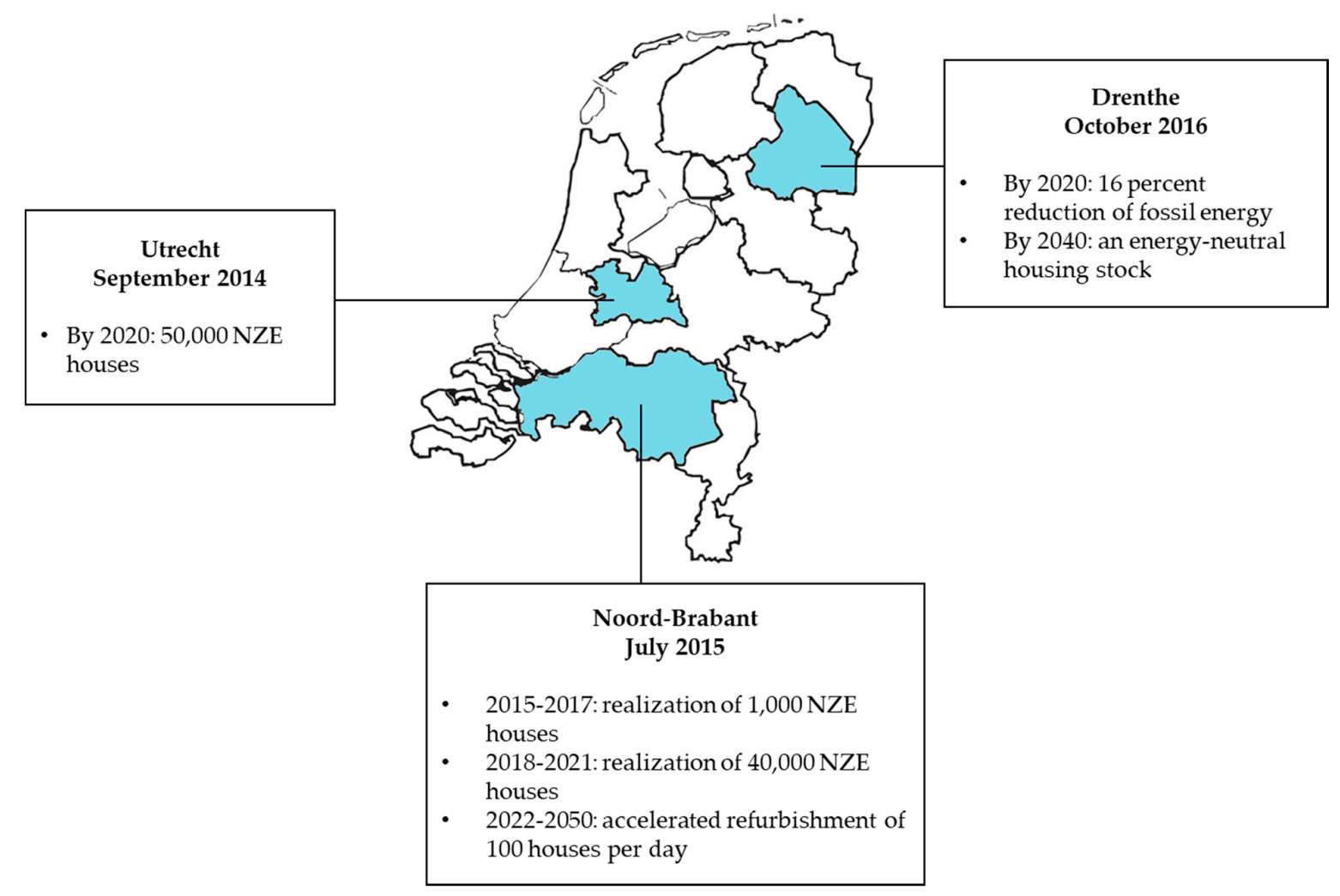

Figure 3. Selected regions in the Netherlands.

\subsection{Data Collection and Analysis}

We applied a variety of data collection and analysis techniques, in line with our focus on cases rather than variables, and comparison of these cases in terms of similarities as well as differences. To determine the pertinent substantive issues, we started our research with eight broad exploratory interviews with experts at both the regional and the national level, held in October and November 2016. We also took part as observers in a network meeting of the Dutch association of 'green' housing associations. At the event, representatives of housing associations, municipalities and business parties discussed their progress on energy-neutral housing in the Netherlands. Furthermore, we collected publicly available documents on the topic and analyzed these documents for pertinent substantive issues.

Based on the data gathered in the exploratory interviews, as well as the information collected from preliminary observation and document study, we fine-tuned our questions for the remaining interviews. In the interviews, we first asked subjects to describe how regional governance arrangements had developed in their region. Subsequently, we posed questions about the current situation regarding regional governance, the specificities of the regional climate and energy problem and existing networks around the problem. We also inquired into the perceived effects of the governance arrangements that were in place. The semi-structured character of the interviews, which we retained throughout our research, allowed interviewees to bring up issues other than the ones we had identified up front.

As part of the exploratory interviews, we asked interviewees to mention actors that they considered to be key in the region. This helped us create an overview of the regional actors involved in energy-neutral housing in the non-profit sector. Municipalities, the provincial administration, housing associations and construction and installation firms were identified as key actors. We then ensured that we selected representatives of at least these actors in every region. Using 'snowball sampling', we compiled a tentative list of interviewees. In subsequent interviews, we continued to use this technique to select interviewees from other organizations, including environmental organizations, 
consultancy firms, and a regional triple helix network organization, as well as consultants in the field of energy-neutral housing.

During the interviews, subjects were asked whether they had documents that could be relevant to our study, in addition to those already studied. Besides publicly available documents, this gave us access to confidential documents, which provided insight into factors influencing regional governance. By collection and analysis of documents and by cross-checking data from these documents with the interview data, we were able to at least partially address a drawback of interviewing key stakeholders: That we might mistakenly take their understanding of 'what causes what' as the truth.

In the period between October 2016 and February 2017, we interviewed 24 people with various regional, sectoral, and professional backgrounds, therewith further increasing the likelihood of attaining valid causal inferences. These interviews all had a semi-structured character, lasted between 30 and $60 \mathrm{~min}$, and were transcribed. Using NVivo software (version 10), we analyzed the transcripts using open, axial and selective coding [56]. We first labelled and categorized the data, inductively but also drawing on the existing literature and taking into account our theoretical expectations. We then related the categories to each other, and finally chose one of the categories to be the core category around which we organized our findings, to which we now turn.

\section{Regional Governance of Energy-Neutral Housing}

\subsection{Utrecht}

In September 2014, the Economic Board Utrecht, a triple helix network of businesses, governments and knowledge institutions, and the Utrecht provincial administration agreed to the objective of realizing 50,000 NZE houses by 2020 as a 'spot on the horizon' (framing). The provincial administration also included the objective in its governing agreement. The two bodies publicly announced their ambition at an Economic Board Utrecht launching event attended by, among others, representatives of the region's housing associations, business parties and municipal governments. However, these actors had not been involved in setting the objective (comprehension). The network event and follow-up communications nonetheless ensured that the objective was known by all relevant regional stakeholders in the field (assessment).

Despite the fact that not all stakeholders were involved, at least not directly (some had been involved indirectly as members of the Economic Board Utrecht), the announcement was received with enthusiasm at the launching event. Though the housing associations and municipalities expressed their willingness to be involved, they were never asked to formally commit to the regional objective. Some of our interviewees recalled an official photograph taken with regional leaders, particularly political ones, posing with the deal. However, the deal was never signed in a formal endorsement of the deal's ambitions.

In the absence of a formal endorsement, interviewees representing the participating parties emphasized that it was unclear to what extent the deal was binding. Moreover, questions and doubts arose about the feasibility of the objective after the official photograph was taken. In particular, political leaders began to worry about the implications. As one interviewee stated, 'After the event political executives thought, "What an ambition! And I have executive responsibility for it too! I would have preferred being involved from the start of the process"' (composition and commitment).

Following the launching event, a 'quartermaster' or process facilitator presented a plan for setting up a regional support structure to achieve the objective of 50,000 NZE houses by 2020. To set up the structure financial contributions were requested from the participating regional actors. The plan, however, was rejected because the actors were unwilling to contribute funds. Thus, even though interviewees indicated that there was enough expertise and information available in the region to achieve the objective (information and expertise), regional financial capacity and authority were lacking (financial resources and authority). 
In an attempt to demonstrate regional leadership (leadership), the Utrecht provincial administration decided to fund an 'NZE alliance' itself. Via this initiative, consultants were paid to help realize concrete projects. At the start of 2017, funding for this alliance was terminated and consultants had begun work on a tender for a follow-up initiative (mode of alignment).

\subsection{Noord-Brabant}

In July 2015, 111 parties-including the provincial administration, municipalities, housing associations, and business parties-agreed on a deal for NZE housing in the Brabant region. In the months prior to the agreement, two process facilitators were appointed to investigate the willingness and needs of these parties, both by approaching them individually and by inviting them to a two-day event with all the interested actors (comprehension). Enthusiasm for participation was overwhelming. The plan garnered considerable attention, and the process facilitators were inundated with phone calls from parties that were willing to join (assessment). All actors that were believed to be necessary for the deal to succeed formally signed the deal (commitment and composition), committing to the objective of 1000 NZE houses by 2017 and 800,000 NZE houses by 2050, the latter number representing the entire housing stock in the region (framing).

After the deal was agreed, the process facilitators organized another meeting. At this event, they presented a plan for a supportive structure, to be financed by contributions from all actors to help achieve the deal's objectives. Similar to Utrecht, actors in Noord-Brabant did not consider the funding plan realistic, which resulted in their rejection of the process facilitators' proposal. Soon thereafter, funding for the two facilitators expired, causing a regional leadership vacuum with regard to achievement of the deal's objectives. Like in Utrecht, however, sufficient information and expertise was deemed available in the Brabant region to realize the NZE housing objectives agreed (information and expertise).

As the municipalities of Tilburg and Den Bosch did not want the entire plan to be off the table, they joined with local housing associations and businesses to establish a 'steering committee' in mid-2016. One interviewee said, 'We appointed people belonging to every "stakeholder group" who would then need to find out how we should advance' (leadership). Every stakeholder group-provincial administration, municipalities, housing associations and business parties-delegated persons with the required authority within their own group (authority). This new steering committee asked for funding again — a smaller amount than before, though — via a letter sent to all of the actors that had signed the deal. The majority of these actors were willing to contribute financially this time, and in this respect, the second call for funding succeeded (financial capacity). The funding made it possible to hire two regional program managers.

At the time of our study, not much further had happened. The steering committee was ironing out its role. It had organized learning sessions for the deal's partners. In the meantime, the committee was keeping the actor group informed of progress via a general newsletter. Additionally, the two regional program managers were catching up with individual interested parties. Our interviewees expressed a general disappointment at the lack of concrete effects of the deal. Much of the enthusiasm present when the deal was signed had dissipated.

\subsection{Drenthe}

In October 2016, governmental organizations, business parties, and housing associations in the region of Drenthe signed a deal to achieve an energy-neutral housing stock by 2040. Interviewees had high expectations of the deal, but emphasized that the real work had yet to begin (mode of alignment). Contrary to what happened in Utrecht and Noord-Brabant, in Drenthe, the actors involved opted for a more open approach regarding how to achieve high levels of energy efficiency. Goals were framed not in numbers of NZE dwellings, but in percentages of fossil energy reduction of the housing stock (this was to equal 100 percent by 2040) (framing). 
Like in Noord-Brabant, the provincial administration of Drenthe hired a consultant to serve as a process facilitator, to investigate the enthusiasm of regional actors for the deal and convince them to formally endorse it. The deal was widely communicated throughout the region, and the number of organizations participating (composition and commitment) -84 at the time of our study-steadily grew (assessment). Resistance mainly came from the housing associations, which doubted the feasibility of the goals. They nonetheless signed the deal, though they added a cover letter expressing their concerns (comprehension).

The provincial administration decided to reserve 6.5 million euros for the deal. Other actors were not requested to contribute financially (financial capacity). Regarding information and expertise, interviewees indicated that the necessary knowledge was available in the region (information and expertise). To support the deal, an organizational structure was developed. The provincial administration delivered what it called an 'expedition leader'. Leadership was shared between this expedition leader and an 'expedition team', in which the different stakeholder groups were represented (authority). The expedition leader emphasized that the aim was not to put himself (and thus the provincial administration) in the lead, but to facilitate a network approach with horizontal relations between members (leadership). The expedition team created 'acceleration teams' in which the different stakeholder groups—-such as the housing associations and business parties—worked together.

\subsection{Differences in Regional Governance of Energy-Neutral Housing}

Comparing regional governance, we found some remarkable differences. In both Noord-Brabant and Drenthe, the agenda was effectively formulated and deliberatively constructed, and the actor group was formally committed. Regarding regional capacity and the mode of alignment, in Noord-Brabant a second call for collaborative funding by the bottom-up regional steering committee succeeded. This resulted in a shared financial capacity that enabled two regional program managers to start work to realize the ambitions. In Drenthe, the provincial administration financed the program and other actors did not have to pay to participate. These actors, however, invested considerable time, in both the expedition and the acceleration teams. The acceleration teams worked together in a clear organizational structure, steered by both the expedition leader and the expedition team. In contrast, in Utrecht, the goals were not set in a deliberative fashion and there was no formal commitment to the goals by the actor group. There was no clear way of working together and no shared regional capacity. Table 3 summarizes these differences in the regional governance of energy-neutral housing.

Table 3. Regional governance in the Utrecht, Noord-Brabant and Drenthe regions.

\begin{tabular}{|c|c|c|c|}
\hline & Utrecht & Noord-Brabant & Drenthe \\
\hline \multirow{2}{*}{ Agenda } & $\begin{array}{l}\text { Clear goals that nonetheless } \\
\text { were not deliberatively set }\end{array}$ & $\begin{array}{l}\text { Clear goals that were } \\
\text { deliberatively set }\end{array}$ & $\begin{array}{l}\text { Clear goals were } \\
\text { deliberatively set }\end{array}$ \\
\hline & $\begin{array}{l}\text { Majority of the interviewees } \\
\text { knew the agenda }\end{array}$ & $\begin{array}{l}\text { Interviewees knew the } \\
\text { agenda }\end{array}$ & $\begin{array}{l}\text { Interviewees knew the } \\
\text { agenda }\end{array}$ \\
\hline \multirow{3}{*}{ Actor group } & Actor group was not clear & $\begin{array}{l}\text { Actor group represented all } \\
\text { major actors }\end{array}$ & $\begin{array}{l}\text { Actor group represented all } \\
\text { major actors }\end{array}$ \\
\hline & $\begin{array}{l}\text { No formal commitment of } \\
\text { actors }\end{array}$ & $\begin{array}{l}\text { Formal commitment of } \\
\text { actors }\end{array}$ & $\begin{array}{l}\text { Formal commitment of } \\
\text { actors }\end{array}$ \\
\hline & $\begin{array}{l}\text { No clear leadership to realize } \\
\text { the goal }\end{array}$ & $\begin{array}{l}\text { Clear leadership by steering } \\
\text { committee }\end{array}$ & $\begin{array}{l}\text { Clear leadership by } \\
\text { expedition team and its } \\
\text { leader }\end{array}$ \\
\hline \multirow[t]{2}{*}{$\begin{array}{l}\text { Regional } \\
\text { capacity }\end{array}$} & $\begin{array}{l}\text { No regional organization or } \\
\text { structure with authority }\end{array}$ & $\begin{array}{l}\text { Representatives of the } \\
\text { stakeholders, each with } \\
\text { authority in their own } \\
\text { stakeholder group, were part } \\
\text { of the steering committee }\end{array}$ & $\begin{array}{l}\text { Representatives of the } \\
\text { stakeholders, each with } \\
\text { authority in their own } \\
\text { stakeholder group, were part } \\
\text { of the expedition team }\end{array}$ \\
\hline & Enough expertise available & Enough expertise available & Enough expertise available \\
\hline
\end{tabular}


Table 3. Cont.

\begin{tabular}{llll}
\hline & \multicolumn{1}{c}{ Utrecht } & \multicolumn{1}{c}{ Noord-Brabant } & \multicolumn{1}{c}{ Drenthe } \\
\hline $\begin{array}{l}\text { Regional } \\
\text { capacity }\end{array}$ & $\begin{array}{l}\text { No shared financial capacity } \\
\text { because the proposed plan } \\
\text { was rejected }\end{array}$ & $\begin{array}{l}\text { All of the actors contributed } \\
\text { financially }\end{array}$ & $\begin{array}{l}\text { Only the provincial } \\
\text { administration provided } \\
\text { money }\end{array}$ \\
\hline $\begin{array}{l}\text { Mode of } \\
\text { Alignment }\end{array}$ & $\begin{array}{l}\text { No shared support } \\
\text { organization }\end{array}$ & $\begin{array}{l}\text { Steering committee } \\
\text { communicated with the } \\
\text { actor group }\end{array}$ & $\begin{array}{l}\text { Expedition leader and } \\
\text { expedition team led the } \\
\text { expedition }\end{array}$ \\
\cline { 2 - 4 } & $\begin{array}{l}\text { Province of Utrecht set up } \\
\text { own program to stimulate } \\
\text { NZE housing by partners in } \\
\text { the region }\end{array}$ & $\begin{array}{l}\text { Regional program managers } \\
\text { organized learning sessions }\end{array}$ & $\begin{array}{l}\text { Acceleration teams worked } \\
\text { on topics such as innovation }\end{array}$ \\
\hline
\end{tabular}

\section{Analyzing Differences in Regional Governance of Energy-Neutral Housing}

\subsection{Functional Logic: Regional Issue Differentiation}

We expected regional governance, first, to be dependent on the functional logic of scale. More precisely, the characteristics of the problem at the regional level and the possibilities available for regional solutions were considered likely to have an effect on the resultant governance of energy-neutral housing in the regions.

Indeed, the regions did differ in the specificities of their housing stock and their suitability for NZE refurbishments. A 2015 study under the auspices of 'Stroomversnelling', a coalition to accelerate NZE building in the Netherlands, assessed the main characteristics making a region suitable for NZE refurbishments. The researchers examined the popularity of residential areas, whether houses had an above or below average energy bill, whether houses were land-based and whether they had been built between 1950 and 1980. Furthermore, they incorporated the value of the dwelling, the characteristics of the owner (privately owned or owned by a housing association with the financial capacity to invest) and whether the area had a high or low turnover of residents. The results of this study indicate that both Utrecht and Noord-Brabant had a relatively high number of suitable dwellings for NZE refurbishments, while Drenthe had fewer suitable dwellings. Moreover, of the ten municipalities identified as the most suitable for NZE refurbishments, six were located in Noord-Brabant, one in Utrecht and none in Drenthe.

We found, however, that regional governance was only partly driven by a functional logic. The differences in the characteristics of the housing stock did generate differences in regional governance, but to a limited extent. In Utrecht, to begin with, the ambition of achieving 50,000 NZE houses by 2020 was high compared to the other regions. One interviewee said that this had been calculated to be a realistic objective. Another interviewee, however, stated that the ambition had been derived straightforwardly from the goal set in the National Energy Agreement; that is, a 10 percent energy reduction by 2020: 'There are 500,000 houses in this province. We said, "We can try to make many houses more energy efficient or we can try to turn 10 percent of all dwellings, so 50,000, into NZE houses."' The provincial administration included the goal, as formulated by the Economic Board Utrecht, in its governing agreement. It welcomed such an initiative, given the relatively large number of houses in the region. Or as one interviewee stated, the provincial administration 'happily embraced' the goal. Moreover, the characteristics of the regional housing stock were not mentioned as being of influence for the regional governance in any of the interviews with representatives of the key parties involved (housing associations, municipalities, businesses, and environmental organizations).

In Noord-Brabant, too, regional governance was not explicitly tailored to the characteristics of the regional housing stock. When asked how the goals of the deal had been set, an interviewee explained, '800,000 NZE houses by 2050. That amounts to refurbishing 150 houses a day. A simple calculation, but it worked great.' In the deal-making process, the national goal of an energy-neutral built environment by 2050 was, as in Utrecht, simply recalibrated to the region of Noord-Brabant. 
Some interviewees stated that this was unfortunate, and referred to the ambition of 800,000 NZE houses as unrealistic. In practice, landmark buildings and very old houses, for example, cannot be refurbished to the standard required. Interviewees, moreover, indicated that the specific characteristics of the region's housing stock did not play a role in conclusion of the NZE deal in Noord-Brabant as the first deal of that nature in the Netherlands.

In Drenthe, we see a similar pattern. The text of the deal states that actors should give 'substance to the National Energy Agreement' and can even accelerate achievement of the NEA goal by cooperation. The deal makes no mention of specific regional characteristics of housing. When referring to the collaboration, several interviewees did, however, recall one element as being particularly relevant: The shrinkage issue. The region of Drenthe, unlike Utrecht and Noord-Brabant, is shrinking in terms of population. Interviewees mentioned this issue as bringing actors closer and strengthening relations between them. Drenthe municipalities were, for example, used to rely on the provincial administration in a wide range of policy fields. The shrinkage issue, and other characteristics of the regional housing market, were not mentioned by interviewees, however, in relation to the development of the deal and the enthusiasm of the actors.

\subsection{Social Logic: Regional Collaboration Structures and Cultures}

We expected regional governance, furthermore, to be influenced by the social logic of community. Particularly, existing regional collaboration structures and cultures were deemed likely to affect the resultant governance of energy-neutral housing in a region.

The three regions differed considerably in their levels of regional community. In Utrecht, the provincial administration had already created a regional energy agenda ('Utrecht 2040') in 2008. In addition, municipalities were working together with the provincial administration in the Utrecht Energy Alliance on the topic of sustainability. Furthermore, the Economic Board Utrecht, a regional triple helix network organization, had a member committee on the topic of the energy transition. Its network on the regional energy agenda was 'non-active', however, and interviewees referred to regional collaboration as difficult to get off the ground. One interviewee stated, 'In other provinces regional networks are much stronger. In Utrecht, it is always a bit disappointing. We don't work that much together.' Interviewees also noted that two municipalities-Utrecht and Amersfoort-were very dominant in the region, because of their relatively large size. One interviewee explained, 'It is probably difficult for the provincial administration to deal with two big municipalities that are mainly concerned with their own business'.

Interviewees in Noord-Brabant emphasized the region's generally strong collaboration structures, for example, between the five largest municipalities (the 'B5 network') and between these municipalities and the provincial administration (BrabantStad). Regarding the energy transition specifically, the Brabant Energy Agreement (BEA) was concluded in March 2015. Noord-Brabant and Gelderland were the only two regions in the Netherlands with such an agreement elaborating the National Energy Agreement at the regional level. Interestingly, the BEA was driven not by government but by representatives of businesses and knowledge institutions. Furthermore, interviewees frequently referred to a 'Brabant' culture. One interviewee noted, 'It works like that here. People just know each other, trust is very important.'

In Drenthe, we found a similarly high level of community as in Noord-Brabant. One interviewee stated, 'I can give another five examples ... We work a lot together and that is on a wide range of topics'. On the energy transition, Drenthe municipalities and the provincial administration were working together in a consultative body on energy and climate. In the field of energy-neutral housing, the Drenthe provincial administration was the first in the Netherlands to conclude a covenant with eight housing associations engaging voluntarily in energy efficiency measures (that deal was reached in 2008). Interviewees frequently referred to Drenthe as being 'small and compact'. This, they said, enhanced collaboration between actors. For instance, the province had only 12 municipalities and eight housing associations. 'We stand pretty close to one another and therefore we know each other', 
one interviewee said, 'so the bureaucratic layers in the province are familiar to us'. Another interviewee stated, 'Though in Drenthe, there also are differences between sub-regions, the region is manageable'.

Indeed, we found regional governance to be highly conditional on community. That it was difficult to organize efforts toward energy-neutral housing in Utrecht followed from the prevailing collaboration culture. The plan presented by one of the process facilitators did not attract enough support. Interviewees blamed the individualistic mentality of the different organizations in the Utrecht region. We saw the same pattern when looking at, for example, collaboration between housing associations. They hardly acted together, having a relatively independent way of working. Additionally, they did not consider regional efforts, like the covenant in Drenthe, to potentially add value in efforts to achieve more NZE housing, as interviewees pointed out.

In Noord-Brabant, by contrast, the regional governance of NZE housing was highly embedded in the already existing collaboration culture and structure. For example, in the months that the process facilitators were gauging enthusiasm for the NZE deal, the Brabant Energy Agreement was signed. The process facilitators locked onto the BEA as anchoring point in the phase of making the NZE deal. As one interviewee explained, 'We used the BEA to get a mandate for our own program.' Together with an enthusiastic city council member, the process facilitators managed to get the objective of 800,000 NZE houses by 2050 incorporated in the agreement. The BEA had a 'gateway effect'. One interviewee described it as allowing 'a kind of anchoring in existing structures to ensure that other individuals and organizations would also become involved in realizing the objective'.

Other strong collaboration structures were also available at the regional level, like the aforementioned 'B5 network'. These were used to disseminate the idea and gain both administrative and political support for the deal on NZE housing. Interviewees pointed out that this made it easier to gain commitment from the five largest municipalities in Noord-Brabant. Furthermore, interviewees noted the particular Brabant collaboration culture, referred to above, as being of influence on the process. 'Something that is brought up at the national level won't necessarily interest someone from Noord-Brabant', one interviewee said. Another interviewee noted the region's preference for self-governance: 'We want to do it ourselves here. We want to have control ourselves, and not be a participant in some national initiative or be governed by the central level. We want to do this. We want to decide on this ourselves.' This culture extended to at least some of the business parties, stimulating them to also commit to the regional deal.

In Drenthe, both the process facilitator and representatives of the Drenthe Environmental Organization, a consultative body on energy and climate, emphasized in interviews that they tried to interact as much as possible with the already established collaborative structures. 'Such structures provided "clues" that were important for a deal to be achieved', one said. Interviewees said that because strong regional collaborations existed, they avoided establishing new structures. For example, upon conclusion of the deal, the aforementioned consultative body was used to disseminate the idea of the 'expedition' and gain support for it. When the deal was finalized, the expedition team was relied upon to set up 'acceleration teams' within the municipalities. Moreover, the collaboration with the region's eight housing associations built on established relationships between the province and the housing associations. In this respect, the initiatives in Drenthe with regard to NZE housing were really customized to the collaboration culture and structure prevailing in the region.

\subsection{Analysis of Regional Differences in Energy-Neutral Housing}

We, finally, expected to find a strong interaction between the specifics of regional governance and the characteristics of the regional climate and energy problem and existing social networks in the regions. We found variation between the selected Dutch regions in both the nature of the regional energy problem and the possibilities for regional solutions, in terms of the local housing stock and the region's suitability for energy-neutral housing. We also found the selected regions to vary in their existing collaboration structures and cultures. Whereas the latter factor seems to have influenced the specific regional governance that emerged, the former factor did not seem to have such an effect. 
The housing stock in Utrecht and Noord-Brabant appeared more appropriate for NZE refurbishment than that in the Drenthe region. In contrast to our expectation, however, regional governance was hardly attuned to these characteristics. The nature of the problem and the potential for solutions did not seem to matter for the efforts organized at the regional level. In accordance with our expectation, the governance of energy-neutral housing was very much aligned to prevailing regional collaboration structures and cultures. In both Noord-Brabant and Drenthe, established regional collaborations on the topic of energy, but also on other issues, were frequently employed to establish an agenda, gain commitment and create regional capacity. In Utrecht, regional collaboration structures and cultures appeared less developed, at least on this particular issue, and if in place at all, they were less used. The fact that a regional support structure, generating regional capacity and allowing for regional coordination, did not succeed, seems to be traceable to a lack of community.

\section{Conclusions and Discussion}

Regions are expected to play a key role in realizing international, European and national climate and energy goals. In the Netherlands, regions have worked on initiatives to realize an energy-neutral housing stock, based on the idea that 'the region' could generate customized solutions. However, up to now, we have lacked knowledge on whether and how regions might actually fulfil this role in practice. In this article, we therefore investigated the factors that shape regional climate and energy governance in the Netherlands, particularly efforts to increase the energy efficiency of urban dwellings. We developed a framework for analysis to describe such efforts, and other 'socially innovative' governance activities, and to explain variation between regions in terms of governance. We applied this framework using a subnational comparative method and a most similar case design.

Zooming in on three Dutch regions-Utrecht, Noord-Brabant and Drenthe-we found that the regional governance of energy-neutral housing varied in terms of the agenda, actor group, regional capacity and mode of alignment. In the Noord-Brabant and Drenthe regions, regional governance appeared to be well-developed, whereas it was much less developed in the Utrecht region. This difference seems to be primarily conditional on the already existing social networks in these regions. In contrast to our expectation based on current policy discourse and the prevailing academic literature, regional governance was hardly tailored to the specific characteristics of the regional built environment. Thus, while regional governance generated solutions that seemed to be supported by key stakeholders, at least in the short term, these solutions were not entirely adapted to the regional situation in terms of its functional characteristics.

How can this be explained? We argue that despite the current policy discourse, the starting point for action in the region with regard to the energy transition, as well as perhaps other issues, is still often 'territory' rather than 'place' and 'space' [13]. Though there is much talk about regionalization of problems and challenges, and the spatially differentiated solutions this requires $[8,57]$, in practice it appears difficult to arrive at legitimate and effective governance at the amorphous scale of the region $[58,59]$. While attempts have been made to experiment with and learn from local and regional solutions, there is a limited degree of social innovation in terms of new roles, new responsibilities and new relationships. In all three regions, actors experienced difficulty early on with regard to achievement of energy-neutral housing, at the stage of framing, assessment and comprehension of the agenda. We surmise that this is because central government was usually the starting point for action in the region. Regional governance processes, notwithstanding the ongoing decentralization of the energy system, still occur primarily in the shadow of developments at the national level.

Beyond the selected regions and the issue of energy-neutral housing, the scientific contribution of our research is threefold. First, we explored the still underdeveloped concept of 'the fluid region', as part of a moderate perspective on the region [5]. We showed the merit of taking the regional problem at hand as the starting point, rather than a particular structure or form. This, for instance, broadened our focus beyond the provincial administrations in the selected cases. That being said, even though the province as an institutional actor did not necessarily dominate arrangements or 
structures, it undoubtedly had a key role in the selected cases as the recognized political authority in an administrative area with fixed territorial boundaries.

Second, we delved into regional governance and the functional and social logics purportedly underlying it. Drawing on recent scholarly work [12,24], we developed a framework for the analysis of regional governance arrangements. The framework helped us to unearth the spatially uneven nature of initiatives and efforts to deal with the challenge of accelerating the energy transition. More specifically, it helped guide our comparison of the differences in the purpose of and capacity for regional sustainability governance and problems of a similar nature (i.e., dynamic problems with a high level of complexity, uncertainty, and ambiguity). Here too, our research found a tendency to narrow the gaze to traditional government systems, actors, policies and instruments.

Third, we demonstrated that regional governance was influenced not only by a functional logic, but that existing social networks and the broader regional context also significantly mattered for the initiatives, efforts and other governance activities that emerged. This was not exclusively positive, however. In the Noord-Brabant case, involvement of actors quickly increased, but their commitment lagged, which negatively impacted the deal's actual implementation (and the implementation of other agreements, such as the Brabant Energy Agreement). Thus, not all novel arrangements, or deals, for regional-level governance 'work', and certainly not in all circumstances.

Clearly, our study has limitations. These offer an agenda for future research. To begin with, we tested our framework for analysis in a preliminary fashion only and on the rather specific issue of climate and energy governance in selected regions of the Netherlands. Additionally, as we focused on selected regions, we paid scant attention to the relationship between these regions and the national level (and beyond). However, these relationships are of crucial importance as part of the multi-level governance system, and may differ according to the preferences and interests of the actors involved in regional networks-despite the uniformizing pressures of, for example, national financial arrangements and legal frameworks. Hence, more research is necessary on the multi-level governance of energy-neutral housing and the role of the region, in the context of the Netherlands, other countries and the broader European and international scene.

Furthermore, especially in such a relatively small country as the Netherlands, regions of course do not operate in splendid isolation from one another-or from central government, for that matter. We found that the deal concluded in Drenthe in October 2016 was influenced by the Brabant NZE deal concluded in July 2015. Such 'case contamination' is inevitable, yet decreases the validity of our results [60]. In addition, our research ended in early 2017. At that point, Drenthe had just embarked on implementation, whereas developments in Utrecht began much earlier, in 2014. This also casts a shadow on the validity of our findings. Further research on other issues and regions is needed to demonstrate whether the framework is helpful beyond the boundaries of our current empirical research and whether it has added theoretical value for better understanding what drives or determines regional governance.

Moreover, we spoke with a limited sample of possible interviewees in the regions. Though they provided a useful overview of new and changing roles, responsibilities and relationships between actors, more detailed insight is necessary, for instance, regarding what roles different actors assumed and why, and what this has meant for the effectiveness and legitimacy of regional governance. More interviews, or surveys, could shed further light on the connections and networks in the regions, and the extent these go beyond the formal administrative definitions of what a region is. To this end, future research could also make use of social network analysis techniques. Additionally, while we sought to ensure the inclusion of as many relevant regional actors as possible in the sample, we cannot rule out that our research was biased toward a certain viewpoint or interest, or toward a certain actor. This may have affected our results. Hence, future research will need to consult a larger group of interviewees or respondents, across a wider set of regional stakeholders, to further advance our understanding of the mechanisms and dynamics at play, and to ensure the validity of our results. 
Finally, knowledge of whether regional governance is tailor-made, and thus aligned with regional problems, can provide only preliminary indications regarding the likelihood that such regional governance will actually contribute to energy-neutral housing and reduction of $\mathrm{CO}_{2}$ emissions. As our cases clearly demonstrate, however, a deal on paper is not the same as a deal in practice, and certainly not the same as an effective deal. The question is how effective such regional governance solutions will be in the long term, beyond having the support of regional actors. To establish long-term effectiveness, not only comparative but also longitudinal research is necessary, following the selected and possibly other, cases over time, and specifying outputs in terms of the number of energy-neutral houses and outcomes in terms of reductions of $\mathrm{CO}_{2}$ emissions.

Author Contributions: L.d.L. and M.G. designed the research; L.d.L. collected the data; L.d.L. and M.G. analyzed and interpreted the data; L.d.L. prepared a draft of the article; M.G. reviewed and edited the draft.

Funding: This research received no external funding.

Acknowledgments: We are grateful to the interviewees for their willingness to contribute to this research. We also thank Arlette van den Berg, Scott Douglas, Petra Hofman, Thomas Hoppe, Michael Verba and Gerdien de Vries for feedback on earlier versions of this article and three anonymous reviewers for their critical comments and constructive suggestions.

Conflicts of Interest: The authors declare no conflict of interest.

\section{References}

1. Filippidou, F.; Nieboer, N.; Visscher, H. Energy efficiency measures implemented in the Dutch non-profit housing sector. Energy Build. 2016, 132, 107-116. [CrossRef]

2. Golubchikov, O.; Deda, P. Governance, technology, and equity: An integrated policy framework for energy efficient housing. Energy Policy 2012, 41, 733-741. [CrossRef]

3. Eurostat. Energy from Renewable Sources; Eurostat: Luxemburg, 2015.

4. Klimaatberaad. Bijdrage van de Sectortafel Gebouwde Omgeving Aan Het Voorstel Voor Hoofdlijnen van Het Klimaatakkoord; Klimaatberaad: The Hague, The Netherlands, 2018.

5. Groenleer, M. De Regio Als Redding? Over de Governance van Ruimte en Plaats in de Netwerksamenleving; Tilburg University: Tilburg, The Netherlands, 2016.

6. PBL Netherlands Environmental Assessment Agency. Ruimtelijke Verkenning 2011. Nederland in 2040-Land van Regio's; PBL: The Hague, The Netherlands, 2011.

7. Rli Raad voor de Leefomgeving en Infrastructuur. Ruimte Voor de Regio in Europees Beleid; Rli: The Hague, The Netherlands, 2015.

8. Studiegroep Openbaar Bestuur. Maak Verschil. Krachtig Inspelen op Regionaal-Economische Belangen; Ministry of the Interior and Kingdom Relations: The Hague, The Netherlands, 2016.

9. Vereniging van Nederlandse Gemeenten (VNG). Ondersteuningsprogramma Energie 2014-2016; VNG: The Hague, The Netherlands, 2014.

10. Ministry of the Interior and Kingdom Relations. Kamerbrief over Uitkomsten Lange Termijn Verkenning Energie in de Gebouwde Omgeving. Kenmerk 2016-0000359889; Ministry of the Interior and Kingdom Relations: The Hague, The Netherlands, 2016.

11. Twynstra Gudde. Analyse Uitkomsten Stakeholderproces 'Verduurzaming Gebouwde Omgeving'; Twynstra Gudde: Amersfoort, The Netherlands, 2016.

12. Foster, K.A.; Barnes, W.R. Reframing regional governance for research and practice. Urban Aff. Rev. 2012, 48, 272-283. [CrossRef]

13. Jessop, B.; Brenner, N.; Jones, M. Theorizing sociospatial relations. Environ. Plan. D Soc. Space 2008, 26, 389-401. [CrossRef]

14. Jones, M. Phase space: Geography, relational thinking, and beyond. Prog. Hum. Geogr. 2009, 33, 487-506. [CrossRef]

15. Keating, M. Contesting European regions. Reg. Stud. 2017, 51, 9-18. [CrossRef]

16. Nair, G.; Gustavsson, L.; Mahapatra, K. Factors influencing energy efficiency investments in existing Swedish residential buildings. Energy Policy 2010, 38, 2956-2963. [CrossRef] 
17. Wilson, C.; Crane, L.; Chryssochoidis, G. Why do homeowners renovate energy efficiently? Contrasting perspectives and implications for policy. Energy Res. Soc. Sci. 2015, 7, 12-22. [CrossRef]

18. Hoppe, T. Adoption of innovative energy systems in social housing: Lessons from eight large-scale renovation projects in the Netherlands. Energy Policy 2012, 51, 791-801. [CrossRef]

19. Hoppe, T.; van der Vegt, A.; Stegmaier, P. Presenting a framework to analyze local climate policy and action in small and medium-sized cities. Sustainability 2016, 8, 847. [CrossRef]

20. Warbroek, B.; Hoppe, T. Modes of governing and policy of local and regional governments supporting local low-carbon energy initiatives; exploring the cases of the Dutch regions of Overijssel and Fryslân. Sustainability 2017, 9, 75. [CrossRef]

21. Pless, S.; Torcellini, P. Net-Zero Energy Buildings: A Classification System Based on Renewable Energy Supply Options; Technical Report NREL TP-550-44586; National Renewable Energy Lab. (NREL): Golden, CO, CA, 2010.

22. Ecofys. Towards Nearly Zero-Energy Buildings. Definitions of Common Principles under the EPBD; Final Report; European Commission: Brussels, Belgium, 2012.

23. Mlecnik, E. Defining nearly zero-energy housing in Belgium and the Netherlands. Energy Effic. 2012, 5, 411-431. [CrossRef]

24. Statistics Netherlands (CBS). Voorraad Woningen; CBS: The Hague, The Netherlands, 2018.

25. Murphy, L.; Meijer, F.; Visscher, H. A qualitative evaluation of policy instruments used to improve energy performance of existing private dwellings in the Netherlands. Energy Policy 2012, 45, 459-468. [CrossRef]

26. Visscher, H.; Meijer, F.; Majcen, D.; Itard, L. Improved governance for energy efficiency in housing. Build. Res. Inf. 2016, 44, 552-561. [CrossRef]

27. Kieft, A.; Harmsen, R.; Hekkert, M.P. Interactions between systemic problems in innovation systems: The case of energy-efficient houses in the Netherlands. Environ. Innov. Soc. Transit. 2017, 24, 32-44. [CrossRef]

28. Hooghe, L.; Marks, G. Community, Scale and Regional Governance: A Postfunctionalist Theory of Governance, Volume II; Oxford University Press: Oxford, UK, 2016.

29. Hoppe, $\mathrm{T} . \mathrm{CO}_{2}$ Reductie in de Bestaande Woningbouw: Een Beleidswetenschappelijk Onderzoek Naar Ambitie en Realisatie. Ph.D. Thesis, University of Twente, Enschede, The Netherlands, 2009.

30. Ministry of the Interior and Kingdom Relations. Convenant Energiebesparing Huursector; Ministry of the Interior and Kingdom Relations: The Hague, The Netherlands, 2012.

31. Tordoir, P.; Poorthuis, A.; Renooy, P. De Veranderende Geografie van Nederland. De Opgaven op Mesoniveau; Atelier Tordoir, Regioplan: Amsterdam, The Netherlands, 2015.

32. Potts, T. The natural advantage of regions: Linking sustainability, innovation, and regional development in Australia. J. Clean. Prod. 2010, 18, 713-725. [CrossRef]

33. Hajer, M. The Energetic Society: In Search of a Governance Philosophy for a Clean Economy; PBL Netherlands Environmental Assessment Agency: The Hague, The Netherlands, 2011.

34. Newig, J. Does public participation in environmental decisions lead to improved environmental quality? Towards an analytical framework. Commun. Coop. Particip. 2007, 1, 51-71.

35. Ansell, C.; Gash, A. Collaborative governance in theory and practice. J. Public Adm. Res. Theory 2008, 18, 543-571. [CrossRef]

36. Sørensen, E.; Torfing, J. Enhancing collaborative innovation in the public sector. Adm. Soc. 2011, 43, 842-868. [CrossRef]

37. Sørensen, E.; Torfing, J. Enhancing Social Innovation by Rethinking Collaboration, Leadership and Public Governance. In Proceedings of the NESTA Social Frontiers: Social Frontiers the Next Edge of Social Innovation Research, London, UK, 14-15 November 2013.

38. Page, S.B.; Stone, M.M.; Bryson, J.M.; Crosby, B.C. Public value creation by cross-sector collaborations: A framework and challenges of assessment. Public Adm. 2015, 93, 715-732. [CrossRef]

39. Ostrom, E. Governing the Commons: The Evolution of Institutions for Collective Action; Cambridge University Press: New York, NY, USA, 1990.

40. Newig, J.; Fritsch, O. Environmental governance: Participatory, multi-level-and effective? Environ. Policy Gov. 2009, 19, 197-214. [CrossRef]

41. Paasi, A.; Metzger, J. Foregrounding the region. Reg. Stud. 2017, 51, 19-30. [CrossRef]

42. Jonas, A.E.G. Region and place: Regionalism in question. Prog. Hum. Geogr. 2012, 36, 263-272. [CrossRef] 
43. Goodwin, M. Regions, territories and relationality: Exploring the regional dimensions of political practice. Reg. Stud. 2013, 47, 1181-1190. [CrossRef]

44. Varró, K.; Lagendijk, A. Conceptualizing the region-In what sense relational? Reg. Stud. 2013, 47, 18-28. [CrossRef]

45. Stone, C.N. Looking back to look forward: Reflections on urban regime analysis. Urban Aff. Rev. 2005, 40, 309-341. [CrossRef]

46. Van Ostaaijen, J.; Horlings, I.; van der Stoep, H. Conditions for vital coalitions in regional development. In Vital Coalitions, Vital Regions: Partnerships for Sustainable, Regional Development; Horlings, I., Ed.; Wageningen Academic Publishers: Wageningen, The Netherlands, 2010; pp. 157-175.

47. Hamilton, D.K. Developing regional regimes: A comparison of two metropolitan areas. J. Urban Aff. 2004, 26, 455-477. [CrossRef]

48. Barnes, W.R.; Foster, K.A.; Malakof, L. Getting Things Done Together: A Workbook for Achieving Goals Regionally; National League of Cities: Washington, DC, USA, 2012.

49. Snyder, R. Scaling down: The subnational comparative method. Stud. Comp. Int. Dev. 2001, 36, 93-110. [CrossRef]

50. Przeworski, A.; Teune, H. The Logic of Comparative Social Inquiry; Wiley-Interscience: New York, NY, USA, 1970.

51. Lijphart, A. Comparative politics and the comparative method. Am. Political Sci. Rev. 1971, 65, 682-693. [CrossRef]

52. Anckar, C. On the applicability of the most similar systems design and the most different systems design in comparative research. Int. J. Soc. Res. Methodol. 2008, 11, 389-401. [CrossRef]

53. George, A.L.; Bennett, A. Case Studies and Theory Development in the Social Sciences; MIT Press: Cambridge, MA, USA, 2005.

54. Bennett, A. Process tracing and causal inference. In Rethinking Social Inquiry: Diverse Tools, Shared Standards, 2nd ed.; Brady, H.E., Collier, D., Eds.; Rowman and Littlefield: Lanham, MD, USA, 2010; pp. 207-219.

55. Energiesprong. Voor de Troepen Uit. Eindrapport Programma Energiesprong 2010-2016; Energiesprong: The Hague, The Netherlands, 2017.

56. Strauss, A.; Corbin, J.M. Basics of Qualitative Research: Grounded Theory Procedures and Techniques; Sage Publications, Inc.: Thousand Oaks, CA, USA, 1990.

57. Groenleer, M.; Stam, E.; Tordoir, P.; Verba, M.; Broekman, C.; Ponds, R. Differentiatie in Regionale Governance en de Relatie Met Economische Groei en Ontwikkeling; Ministry of the Interior: The Hague, The Netherlands, 2018.

58. Brenner, N.; Jessop, B.; Jones, M.; MacLeod, G. State/Space: A Reader; Blackwell Publishing: Malden, MA, USA, 2002.

59. Agnew, J.A. Territory, politics, governance. Territ. Politics Gov. 2013, 1, 1-4. [CrossRef]

60. Rosenthal, U. en P.'t, Hart, Het één en het ander: Case-contaminatie en andere methodologische complicaties in beleidswetenschappelijk onderzoek. Beleidswetenschap 1994, 8, 141-163.

(C) 2018 by the authors. Licensee MDPI, Basel, Switzerland. This article is an open access article distributed under the terms and conditions of the Creative Commons Attribution (CC BY) license (http:/ / creativecommons.org/licenses/by/4.0/). 